\title{
ANTIMICROBIAL ACTIVITY OF ETHANOLIC EXTRACTS OF CLOVE AND THYME
}

\author{
$[45]$ \\ Yasmin R. Aboelazab, Abdel-Fattah A.A., Khallaf M.F. and El-Kenany Y.M. \\ Food Science Dept., Fac. of Agric. Ain Shams Univ., P.O. Box 68, Hadayek Shubra 11241, \\ Cairo, Egypt \\ *Corresponding author: abdeo1978@agr.asu.edu.eg
}

Received 9 January, 2019

Accepted 27 January, 2019

\begin{abstract}
This study was carried out to evaluate the antimicrobial activity of clove (Syzygium aromaticum) and thyme (Thymus vulgaris) ethanolic extracts. Different concentrations of ethanolic extracts were prepared and antimicrobial activity was determined against some bacterial, yeast and mold strains. The antimicrobial activity of examined extracts at different concentrations was determined against different cell population of tested strains and expressed as diameter of inhibition zone. Results showed that all clove and thyme ethanolic extracts were markedly inhibited the growth of all tested strains, however, the inhibition effect was differed with regard to the concentration of ethanolic extract as well as the type of tested microorganism. Generally, clove ethanolic extract had stronger antimicrobial activity rather than that of thyme ethanolic extract. Subsequently, clove and thyme are an extremely strong antimicrobial agent with usefull potential applications in food processing as a natural safe unsted of synthetic antimicrobial agents.
\end{abstract}

Keywords: Clove, Thyme, Extraction and Antimicrobial activity.

\section{INTRODUCTION}

The use of antimicrobial agents is a common practice for preserving foods; incorporation in a food recipe of chemical antimicrobial agents towards inhibition of spoilage and pathogenic microorganisms resulted in compositional modification of food environment. This application or treatment is nowadays undesirable for the consumer, who likes natural products, and minimally processed foods of high quality, with a fresh appearance, easy to eat, tasty, prepared without chemical preservatives, safe and possessing long shelf-life (Lucers et al 2012.

Spices and medicinal plants are cansidered as natural antimicrobial and antioxidant. Spices and some medicinal plants have been used in traditional medicines from many thousand years ago. (Tajkarimi et al 2010; Pandit et al 2011 and Rani et al 2012

Most of food borne bacterial pathogens are sensitive to extracted plants such as garlic, turmeric, cinnamon, clove, thyme and oregano. Clove (Syzygium aromaticum) is one of the major spices containing natural antimicrobial and antioxidant components. It commonly consumed as most popular medicinal herbs around the world and it is originates from India, Southeast of Asia and Indonesia. Generally, the powder produced from this natural product has been commercially used as a spice, flavorent, preservative and additive. Besides, it is also utilized as a therapeutic agent used in several foods; because of its low side effects (Zhang et al 2006; Rani et al 2012 and Koul et al 2013).

The natural phytochemical components in thyme such as thymol was reported to possess numerous medicinal properties and wide spectrum of biological actions which include; antioxidant, anticarcinogenic, antiinflammatory, antimutagenic, anticoagulant, antidiabetic, antifertility and antimicrobial activities (Nikoli'c et al 2014 and Sandhir et al 2015); also reported therapeutic property against a variety of diseases ranging from cancer to cystic fibrosis and this provides a basis for exploring its endodontic applications. Thymol are is a natural monoterpenoid phenol component known 
to have strong antimicrobial and antioxidant activities (Prasanna et al 2011 and Nikoli'c et al 2014). This compound due to a variety of biological activities has been gained significant attention of researches all over the world.

The aim of study was to evaluate antimicrobial activity of prepared ethanolic powder extracts of clove and thyme that used as natural antimicrobial in food products.

\section{MATERIALS AND METHODS}

\section{Materials}

Clove (Syzygium aromaticum) and thyme (Thymus vulgaris) powders ware purchased during 2017 from local market, Cairo, Egypt. All chemicals and reagents were analytical grade produced by Sigma-Aldrich, Inc. (St. Louis, M., USA); also all media used in determination of antimicrobial activity were produced by Oxoid Limited (England) and purchased from EL. Gomhouria Trading Chemicals and Drugs Company.

The tested microorganisms are: bacterial strains included; Bacillus cereus DSMZ 345, Staphylococcus aureus ATCC 6528, Escherichia coli ATCC 25922, and Salmonella typhimurium ATCC 14028; while yeast strains included: Candida albicans ATCC 10231 and Geotricum candidum NRRL Y-552 and finally mold strains included; Aspergillus niger ATCC 102 and Aspergillus flavus. The aforementioned strains were obtained from the Egyptian Microbial Culture Collection (EMCC) at the Microbial Resource Center (Cairo, MIRCEN), Faculty of Agriculture, Ain Shams University, Cairo, Egypt.

\section{Methods}

Preparation of clove and thyme ethanolic extracts

Plant materials were ground and macerated for extracting. Dried clove and thyme powder samples $(5 \mathrm{~g})$ were homogenized for $1 \mathrm{~min}$ in $50 \mathrm{~mL}$ of $80 \%$ ethanol and $2 \mathrm{ml}$ dimethyl sulfoxid (DMSO), extraction was carried out by shaking overnight at 1,500 rpm at room temperature. Then, ethanolic clove and thyme extracts were centrifuged at 3,000 rpm for $15 \mathrm{~min}$ and filtered through $0.22 \mu \mathrm{m}$ poly-tetrafluoethylene (PTFE) filters, the residue was reextracted twice, (Carvalho et al 2015).

\section{Determination of antimicrobial activity of clove and thyme ethanolic extracts}

\section{Preparation of inoculates}

Stock cultures of tested bacterial strains were activated by loopful of stock culture into nutrient broth medium and incubated at 30 or $37^{\circ} \mathrm{C}$ for 24 $\mathrm{h}$. then the incubated suspensions of tested strains were enumerated using plate count method. The abovementioned procedure was repeated for tested yeast strains using potato dextrose broth medium and incubated at $28-30^{\circ} \mathrm{C}$ for $48-72 \mathrm{~h}$ with regular shaking. They were counted using plate count method on potato dextrose agar medium. Finally, the tested mold strains which were intended to achieve the antifungal assay were prepared as follows: stock cultures were activated on potato dextrose agar medium after acidification which was immediately poured into Petri dishes $(90 \mathrm{~mm})$. Stock cultures were activated by seeding the plates in the center with $5 \mathrm{~mm}$ agar disc of 7 days old culture of tested fungi which were grown on the same medium, and then the plates were incubated for $7-10$ days at $28^{\circ} \mathrm{C}$.

\section{Screening of the antimicrobial activity against bacterial and yeast strains}

The paper disc diffusion technique was used as screening method to determine the antimicrobial activity of clove and thyme ethanolic extracts against bacterial and yeast strains, the method of Lai et al (2009) was used with some modifications as follows: About $3 \mathrm{ml}$ of soft nutrient agar $(0.75 \%$ agar) containing $50 \mu \mathrm{l}$ inoculums of tested bacterial strain was layered over $20 \mathrm{ml}$ of hard nutrient agar containing (2.0\% agar), while about $3 \mathrm{ml}$ of soft potato dextrose agar ( $0.75 \%$ agar) containing $50 \mu \mathrm{l}$ inoculums of tested yeast strain was layered over $20 \mathrm{ml}$ of hard potato dextrose agar containing (2.0\% agar). Sterilized filter paper discs $(6 \mathrm{~mm}$ of diameter) were injected with $15 \mu$ of different concentrations $2.5-25(\mathrm{mg} / \mathrm{ml})$ of clove and thyme ethanolic extracts. The injected discs were put in the middle of plates, and then plates were incubated at 30 or $37^{\circ} \mathrm{C}$ for $28 \mathrm{~h}$ for bacteria and at $28-30{ }^{\circ} \mathrm{C}$ for $48 \mathrm{~h}$ for yeasts.

The principle behind the assay technique is fairly simple; when an antibiotic injected disc is placed on agar previously inoculated with the rest organism and on moistening, the antibiotic diffuses rapidly outwards through the agar producing antibiotic concentration gradient. A clear zone or ring 
will present if the agent inhibit microbial growth. The wider zones surrounding the disc indicated that substance is more active. The zone diameter of inhibition around each of the discs (disc diameter included) was taken as measure of antimicrobial activity. All tests were performed in duplicates. Negative control was prepared using $15 \mu \mathrm{l}$ of ethanol with DMSO solution.

Determination of the minimal inhibitory concentrations (MICs), bacteriostatic and bactericidal effects

The antimicrobial activity of clove and thyme ethanolic extracts against both Gram-positive, Gram-negative bacteria and yeast strains were examined by detecting the minimum inhibitory concentrations (MICs),. The appropriate concentrations of clove and thyme ethanolic extracts; which selected as MICs were added to $25 \mathrm{ml}$ of nutrient broth for bacterial strains, and potato dextrose broth for yeast strains. The broth media were inoculated with $50 \mu \mathrm{l}$ of tested strains. Different flasks were incubated at $37^{\circ} \mathrm{C}$ (St. aureus, E. coli and S. typhimurium) and at $30^{\circ} \mathrm{C}$ (B. cereus, C. albicans and $G$. candidum) with regular shaking for $24 \mathrm{~h}$. Every 4 hours, growth was compared with the control broth visually and through the measurement of the log number of colony forming units (log cfu/ ml) by plate count procedure (Rachana and Venugopalan, 2014).

\section{Determination of antifungal activity}

The antifungal activity of clove and thyme ethanolic extracts was estimated using a growth inhibition assay technique (agar dilution method), described by (Guo et al 2007). Fungal spores were grown on petri dishes filled with potato dextrose agar medium. After 7 days of incubation at $28^{\circ} \mathrm{C}$, the fungal plates were stored in a refrigerator at 5 ${ }^{\circ}$ C. To test the antifungal effect; different prepared of clove and thyme extracts were added aseptically to sterile melted PDA media to prepare the concentrations $(10,20,30,40$, and $50 \mathrm{mg} / \mathrm{ml})$ and divided into two groups (duplicate for each was carried out). To each plate in the experimental group (E), an appropriate amount of the clove and thyme extracts was added. To those of control group (C), an equal amount ethanol with DMSO solution was added. After plates were cooled, the fungal inoculums were placed onto the agar surface. Both groups were incubated for 3-5 days at $28^{\circ} \mathrm{C}$. The diameters of the largest and smallest fungal colonies were recorded and the averages were calculated.

The antifungal in terms of inhibition percent of mycelia growth (antifungal index) was calculated after mycelium of fungi was reached the edges of control plates as follows:

\section{Antifungal index (\%) $=[(C-E) / C] \times 100$}

Where C: the average diameter of the largest and smallest colonies of control groups.

$\mathrm{E}$ : the average diameter of the largest and smallest colonies of the experimental groups.

If the inhibition ratio as antifungal index (\%) was greater than $20 \%$, the test strains would be considered inhibited and the minimal inhibitory concentration (MIC) of thase strains were then determined.

\section{RESULTS AND DISCUSSION}

Antimicrobial activity of prepared clove and thyme ethanolic extracts

\section{Preliminary screening of antimicrobial activity}

In vitro, preliminary screening of the antimicrobial activities of clove and thyme ethanolic extracts at different concentrations against four strains of pathogenic bacteria and two yeast strains, were determined and the results are given in Tables (1 and 2).

The antibacterial activity values of clove and thyme ethanolic extracts at different concentrations against pathogenic bacteria were assayed and the measured inhibition zone diameters $(\mathrm{mm})$ are represented in Table (1). The control plates for all bacterial strains which treated with ethanol and DMSO did not show any inhibitory effect against all tested bacterial strains. Where, the clove and thyme crude ethanolic extracts were able to inhibit markedly the growth of all tested bacterial strains; however, the effects differed with regard to the concentration of ethanolic extracts and tested bacterial strain.

The antimicrobial activity of clove and thyme ethanolic extracts was exhibited obviously with the increasing of the extract concentration. Additionally, clove ethanolic extracts significantly demonstrated stronger antimicrobial activity compared to thyme ethanolic extracts (Xie et al 2015). Clove and thyme ethanolic extracts generally showed stronger antibacterial activity against examined Gram-positive bacterial strains than those of Gram- 
negative bacterialanes; it was ranged between (10 - $15 \mathrm{mg} / \mathrm{ml}$ ) for clove ethanolic extracts; and also ranged between $(15-20 \mathrm{mg} / \mathrm{ml})$ for thyme ethanolic extracts. B. cereus and St. aureus strains observed more sensitivity in presence of both clove and thyme ethanolic extracts compered to E. coli and
S. typhimurium. Concerning the obtained inhibition zones diameter were $29,32,31$, and $32 \mathrm{~mm}$, respectively for clove ethanolic extracts; when thyme ethanolic extracts were examined, whereas their measured diameter were 25, 28, 28 and $24 \mathrm{~mm}$, respectively.

Table 1. Antimicrobial activity of clove ethanolic extract against bacterial and yeast strains

\begin{tabular}{|c|c|c|c|c|c|c|c|c|c|c|c|c|}
\hline \multirow{2}{*}{ Strains } & \multirow{2}{*}{$\begin{array}{l}\text { Conc. } \\
\text { (mg/ml) }\end{array}$} & \multicolumn{10}{|c|}{ Diameter of inhibition zones (mm.) } & \multirow{2}{*}{$(\mathrm{mg} / \mathrm{ml})$} \\
\hline & & 2.5 & 5 & 7.5 & 10 & 12.5 & 15 & 17.5 & 20 & 22.5 & 25 & \\
\hline B. cereus & & 9 & 15 & 24 & 29 & 29 & 29 & 30 & 29 & 30 & 30 & 10 \\
\hline St. aureus & & 10 & 19 & 26 & 32 & 32 & 32 & 32 & 33 & 32 & 31 & 10 \\
\hline E. coli & & 8 & 14 & 19 & 22 & 27 & 31 & 31 & 30 & 31 & 32 & 15 \\
\hline S. typhimurium & & 8 & 17 & 24 & 26 & 28 & 32 & 32 & 31 & 30 & 31 & 15 \\
\hline C. albicans & & 12 & 19 & 25 & 32 & 32 & 32 & 31 & 33 & 23 & 32 & 10 \\
\hline G. candidum & & 11 & 17 & 24 & 28 & 33 & 34 & 34 & 33 & 34 & 34 & 15 \\
\hline
\end{tabular}

* Including disc diameter of $6 \mathrm{~mm}$.

Table 2. Antimicrobial activity of thyme ethanolic extract on bacterial and yeast strains

\begin{tabular}{|c|c|c|c|c|c|c|c|c|c|c|c|c|}
\hline \multirow{2}{*}{ Strains } & \multirow{2}{*}{$\begin{array}{l}\text { Conc. } \\
(\mathrm{mg} / \mathrm{ml})\end{array}$} & \multicolumn{10}{|c|}{ Diameter of Inhibition Zones (mm.) } & \multirow{2}{*}{$\begin{array}{l}\text { MICs }^{* *} \\
(\mathrm{mg} / \mathrm{ml})\end{array}$} \\
\hline & & 2.5 & 5 & 7.5 & 10 & 12.5 & 15 & 17.5 & 20 & 22.5 & 25 & \\
\hline B. cereus & & 10 & 14 & 17 & 22 & 24 & 25 & 25 & 25 & 26 & 26 & 15 \\
\hline St. aureus & & 9 & 15 & 19 & 26 & 27 & 28 & 28 & 29 & 28 & 28 & 15 \\
\hline E. coli & & 8 & 13 & 18 & 19 & 23 & 25 & 26 & 28 & 28 & 27 & 20 \\
\hline S. typhimurium & & 9 & 12 & 14 & 17 & 19 & 21 & 23 & 24 & 24 & 23 & 20 \\
\hline C. albicans & & 11 & 14 & 17 & 24 & 25 & 26 & 26 & 27 & 26 & 26 & 25 \\
\hline G. candidum & & 12 & 16 & 21 & 25 & 27 & 29 & 29 & 28 & 29 & 30 & 15 \\
\hline
\end{tabular}

* Including disc diameter of $6 \mathrm{~mm}$.

${ }^{* *}$ MIC: Minimal inhibitory concentration.

It could be noticed that, B.cereus and St. aureus were the most sensitive tested strains, with the MICs value $(10 \mathrm{mg} / \mathrm{ml})$ in the presence of the clove ethanolic extract and with MICs value $(15 \mathrm{mg} / \mathrm{ml})$ in the presence of the thyme ethanolic extract.

Figures (1 and 2) illustrated that, the antibacterial effects of both determined clove and thyme ethanolic extract concentrations; which were recorded as MICs values showed bactericidal effect.
Generally, ethanolic extracts of clove had a stronger antimicrobial effect on Gram-positive bacteria rather than Gram-negative ones by components present as active ingredients (phenylpropanoides) such as carvacrol, thymol, eugenol and cinnamaldehyde. These compounds inducing leakage of ions and cell contents, leading to cell death (Amrita et al 2009; Tongnuanchan and Benjakul, 2014). 

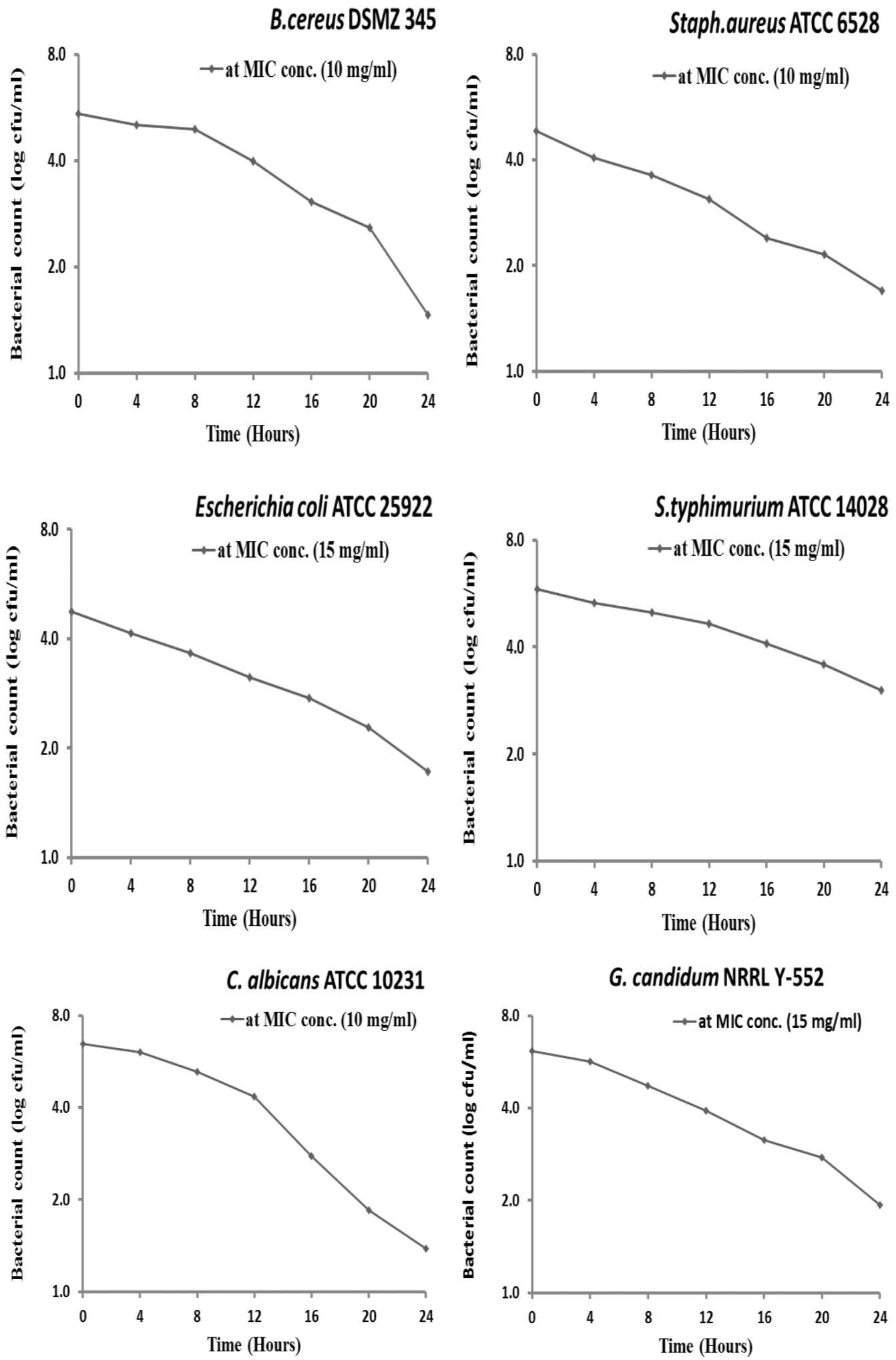

Fig. 1. Growth behavior of examined strains in presence of detected MICs values $(\mathrm{mg} / \mathrm{ml})$ of clove ethanolic extract. 

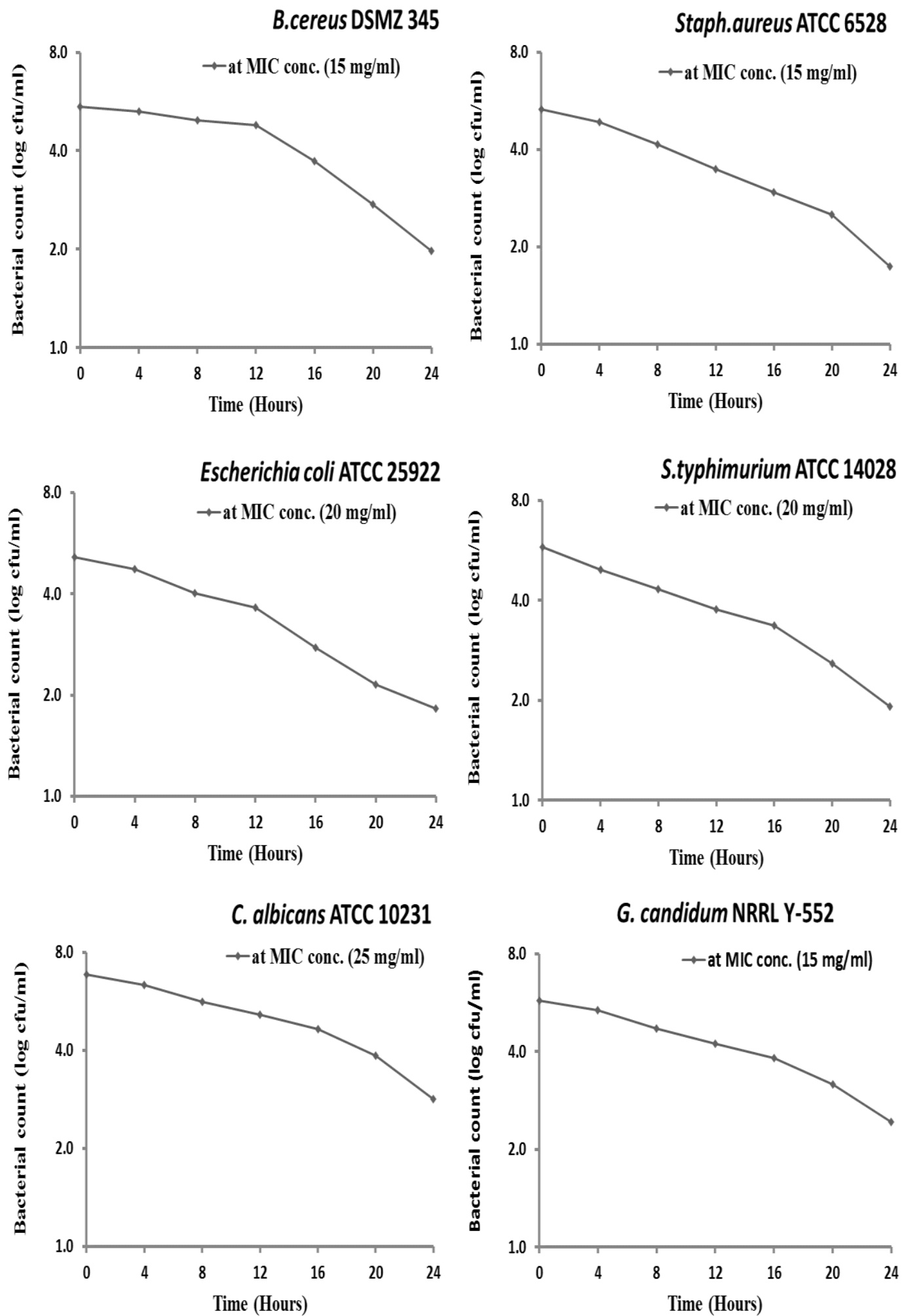

\section{G. candidum NRRL Y-552}

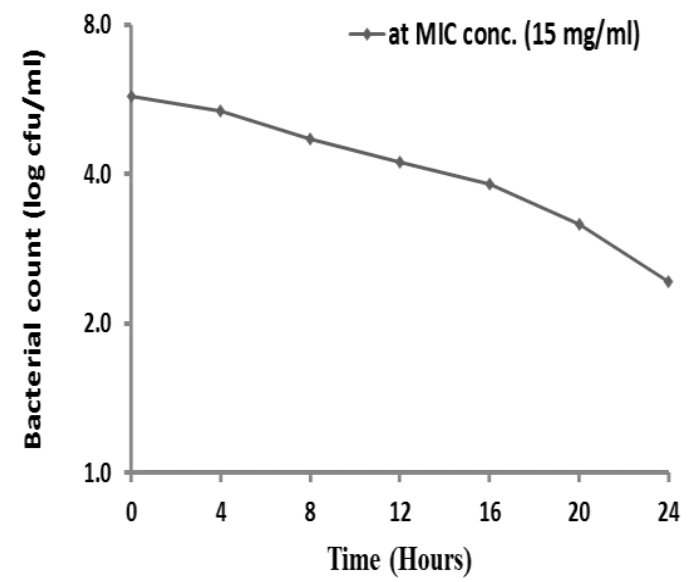

Fig. 2. Growth behavior of examined strains in presence of detected MICs values $(\mathrm{mg} / \mathrm{ml})$ of thyme ethanolic extract 
On the other side, the observed more resistance of tested Gram-negative bacterial strains could be due to extrinsic membrane proteins and lipopolysaccharides. The minimum inhibitory concentrations (MICs) of clove ethanolic extracts at concentration of $2.5-25(\mathrm{mg} / \mathrm{ml})$ were presented in Tables (1 and 2), and the different MICs values ranged from 10 to $15(\mathrm{mg} / \mathrm{ml})$ for clove ethanolic extracts; and 15 to $20(\mathrm{mg} / \mathrm{ml})$ for thyme ethanolic extracts.

Antimicrobial of clove and thyme ethanolic extracts against examined yeast strains are summarized in Tables (1 and 2). Clove and thyme ethanolic extracts inhibited the growth of two tested yeast strains. Moreover, the antimicrobial effect against examined yeast strains was strengthened as the concentration of ethanolic extract increased. Clove ethanolic extracts generally showed stronger antimicrobial activity compare to thyme ethanolic extracts (Tongnuanchan and Benjakul, 2014).

\section{Antifungal activity of clove and thyme ethanolic extracts}

Data presented in Tables (3 and 4) showed the antifungal activity of clove ethanolic extracts. The different concentrations of clove ethanolic extract were able to inhibit the mycelia growth of two examined fungal strains. Antifungal effect was noticed when concentration of clove extracts were increased from 10 to $50(\mathrm{mg} / \mathrm{ml})$. The MICs values of clove ethanolic extracts was $10(\mathrm{mg} / \mathrm{ml})$, whereas it was $30(\mathrm{mg} / \mathrm{ml})$ for thyme ethanolic extracts. The highest antifungal index (\%) was found at concentration of $50 \mathrm{mg} / \mathrm{ml}$.

Table 3. Antifungal activity of clove ethanolic extract against fungal strains

\begin{tabular}{|c|c|c|c|c|c|c|c|}
\hline \multirow{2}{*}{$\begin{array}{l}\text { Fungal } \\
\text { Strains }\end{array}$} & \multirow{2}{*}{$\begin{array}{c}\text { Conc. } \\
\text { (mg/ml) }\end{array}$} & \multicolumn{5}{|c|}{ Antifungal index (\%) } & \multirow{2}{*}{$\begin{array}{c}\text { MIC } \\
(\mathrm{mg} / \mathrm{ml})\end{array}$} \\
\hline & & 10 & 20 & 30 & 40 & 50 & \\
\hline A. niger & & 24 & 39 & 42 & 48 & 51 & 10 \\
\hline A. flavus & & 25 & 32 & 37 & 43 & 59 & 10 \\
\hline
\end{tabular}

Table 4. Antifungal activity of thyme ethanolic extract against fungal strains

\begin{tabular}{|c|c|c|c|c|c|c|c|}
\hline \multirow{2}{*}{$\begin{array}{l}\text { Fungal } \\
\text { Strains }\end{array}$} & \multirow{2}{*}{$\begin{array}{l}\text { Conc. } \\
(\mathrm{mg} / \mathrm{ml})\end{array}$} & \multicolumn{5}{|c|}{ Antifungal index (\%) } & \multirow{2}{*}{$\begin{array}{c}\text { MIC } \\
(\mathrm{mg} / \mathrm{ml})\end{array}$} \\
\hline & & 10 & 20 & 30 & 40 & 50 & \\
\hline A. niger & & 9.3 & 14.6 & 21.5 & 27.0 & 28.3 & 30 \\
\hline A. flavus & & 11.5 & 15.7 & 26.3 & 28.3 & 32.5 & 30 \\
\hline
\end{tabular}

\section{CONCLUSION}

The obtained results of antimicrobial activities showed that clove and thyme ethanolic extracts inhibited the growth of all tested strains; in generally clove ethanolic extracts exhibited significantly stronger antimicrobial activity compared to thyme ethanolic extracts. It could be considered that clove and thyme are natural material rich in active ingredients content with extremely strong antimicrobial efficiency.

\section{REFERENCES}

Amrita V., Sonal D. and Shalini R. 2009. Antibacterial Effect of Herbs and Spices Extract on
Escherichia coli. Electronic Journal of Biology, 5(2), 40-44.

Carvalho D.M., Takeuchi K.P., Geraldine R.M., Mdura C.J. and Tdrres M.C. 2015. Production, solubility and antioxidant activity of curcumin nanosuspension. Food Sci. Technol., Campinas; 35(1), 115-119.

Guo Z., Xing R., Liu S., Zhong Z., Ji X., Wang L. and Li P. 2007. The influence of the cationic of quaternized chitosan on antifungal activity. International J. Food Microbiol., 118, 214 217.

Koul O., Singh R., Kaur B. and Kanda D. 2013. Comparative study on the behavioural response and acute toxicity of some essential oil compounds and their binary mixtures to larvae 
of Helicoverpa armigera, Spodoptera litura and Chilo partellus. Ind. Crops Prod; 49, 428-436.

Lai H.Y., Lim Y.Y. and Tan S.P. 2009. Antioxidative, tyrosinase inhibiting and antibacterial activities of leaf extracts from medicinal ferns. Biosci. Biotech. Biochem.; 73,1362-1366.

Lucers A., Costa C., Conte A. and Del-Nobile M.A. 2012. Food applications of natural antimicrobial compounds. Froutiers in Microbiology; 287, 1-13.

Nikoli'ca M., Glamo J., Ferreirab I., Ricardo C., Fernandesb A., Markovi'c T. Markovi'c D., Giwelie A. and Sokovi'c A. 2014. Chemical composition, antimicrobial, antioxidant and antitumoractivity of Thymus serpyllum L., Thymus algeriensis Boiss. and Reut andThymus vulgaris $\mathrm{L}$. essential oils. Industrial Crops and Products 52, 183- 190.

Pandit S., Kim H., Kim J. and Jeon J. 2011. Separation of an effective fraction from turmeric against Streptococcus mutans biofilms by the comparison of curcuminoid content and antiacidogenic activity. Food Chem. 126, 15651570.

Prasanna N., Nithya J. and Nabeel N. 2011. Ethnopharmacological approach in Endodontic Treatment: A Focused, Review. Int. J. Drug Dev. \& Res. 3(4), 68-77.

Rachana S. and Venugopalan P. 2014. Antioxidant and bactericidal activity of wild turmeric extracts. J. of Pharmacognosy and Phytochemistry 2(6), 89-94.

Rani B., Kachhawa G.R., Yadan R.K., Chauhan V. and Maheshwari R. 2012. Phytochemical effectiveness of clove oil: A review. Int. J. of Research in Pharmacology \& Pharmacotherapeutics, 1, 230-233.

Sandhir R., Yadav A., Sunkaria A. and Singhal N. 2015. Nano-antioxidants: An emerging strategy for intervention against neurodegenerative conditions. Neurochemistry Int. 89, 209226.

Tajkarimi M.M., Ibrahim S.A. and Cliver D.O. 2010. Antimicrobial herb and spice compounds in food. Food Control, 21, 1199-1218.

Tongnuanchan P. and Benjakul S. 2014. Essential oils: extraction, bioactivities, and their uses for food preservation, J. of Food Science, 79(7), 1231-1249.

Xie Y., Yang Z., Cao D., Rong F., Ding H. and Zhang D. 2015. Antitermitic and antifungal activities of eugenol and its congenersfrom the flower buds of Syzgium aromaticum (clove). Industrial Crops and Products 77, 780-786.

Zhang H., Mardyani S., Chan W.C. and Kumacheva E. 2006. Design of biocompatible chitosan microgels for targeted $\mathrm{pH}$-mediated intracellular release of cancer therapeutics. Biomacro molecules, 7(5), 1568-1572. 


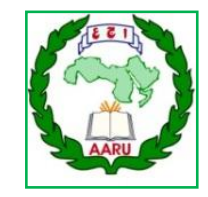

المؤتمر الرابع عشر لبحوث التنمية الزراعية،

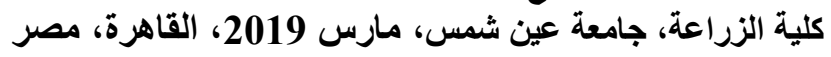
مجلا(27)، عدد(1)، عدد خاص مارس،

\section{النشاط المضاد للميكرويات لمستخلصات القزنفل والزعتر الإيثانولية}

[45]

ياسمين روحى أبو العزب - عبد الفتاح عبد الكريم عبد الفتاح - محمد فرج خلاف - يوسف مرسي الكناني

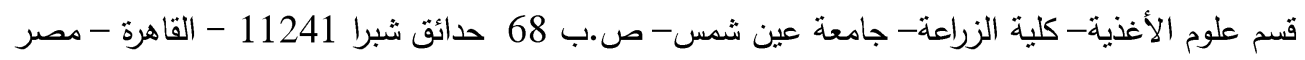

${ }^{*}$ Corresponding author: abdeo1978@agr.asu.edu.eg

\begin{tabular}{|c|c|}
\hline 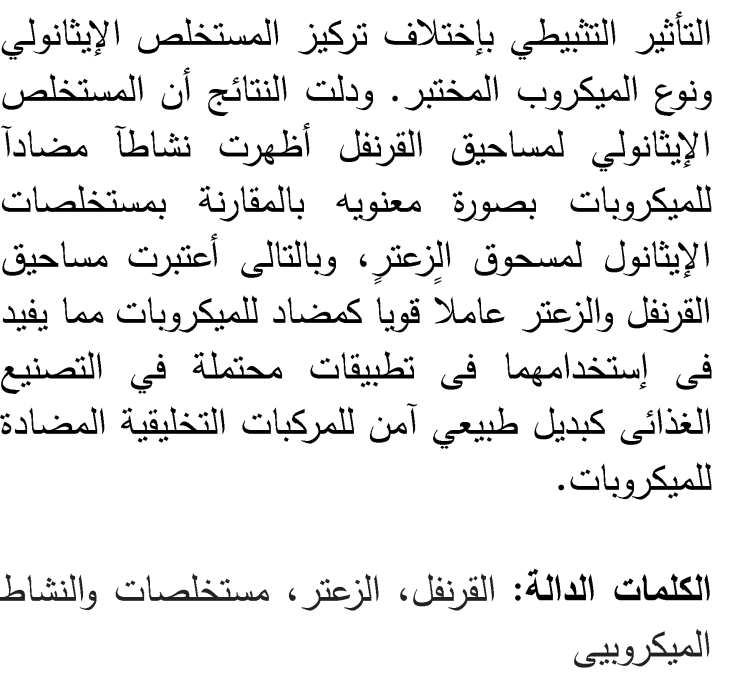 & 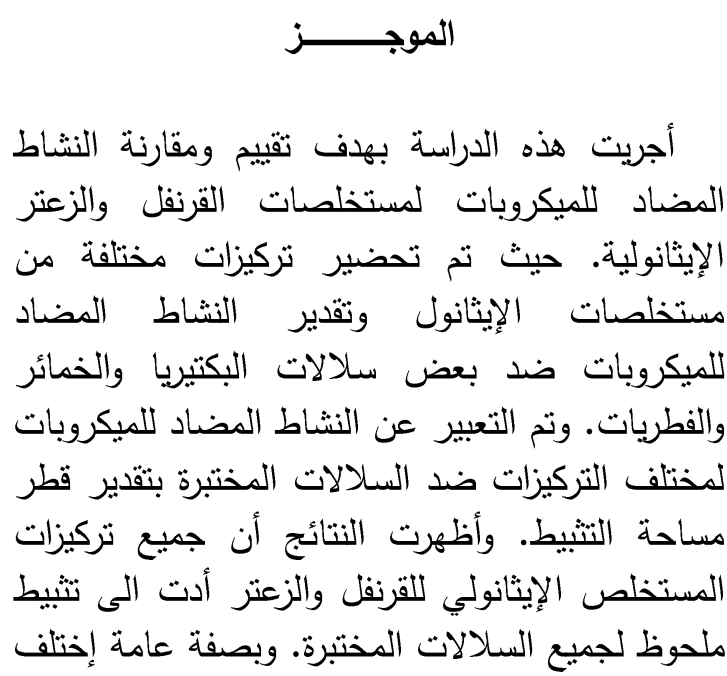 \\
\hline
\end{tabular}

